Abstract 577 Table 2 Multivariable analysis of risk factors for endometrial cancer recurrence

\begin{tabular}{|c|c|c|c|c|}
\hline Predictor & No. of cases & HR & $95 \% \mathrm{Cl}$ & $P$-value \\
\hline $\begin{array}{l}\text { Stage } \\
\text { IA } \\
\geq 1 \mathrm{~B}^{*} \\
\end{array}$ & $\begin{array}{l}192 \\
503 \\
\end{array}$ & 1.77 & 1.02 to 3.07 & 0.04 \\
\hline $\begin{array}{l}\text { Grade } \\
1-2 \\
3 \\
\end{array}$ & $\begin{array}{l}602 \\
93 \\
\end{array}$ & 2.42 & 1.28 to 4.58 & 0.01 \\
\hline $\begin{array}{l}\text { LVSI } \\
\text { none or mild } \\
\text { substantial }\end{array}$ & $\begin{array}{l}664 \\
31 \\
\end{array}$ & 3.90 & 2.07 to 7.37 & $<0.0001$ \\
\hline $\begin{array}{l}\text { LICAM } \\
\leq 10 \% \text { (negative) } \\
>10 \% \text { (positive) }\end{array}$ & $\begin{array}{l}659 \\
36 \\
\end{array}$ & 2.32 & 1.12 to 4.83 & 0.02 \\
\hline $\begin{array}{l}\text { TCGA } \\
\text { MMRd } \\
\text { POLE mutant } \\
\text { p53 abnormal } \\
\text { NSMP } \\
\end{array}$ & $\begin{array}{l}198 \\
43 \\
31 \\
423 \\
\end{array}$ & $\begin{array}{l}1 \\
0.34 \\
2.11 \\
0.70 \\
\end{array}$ & $\begin{array}{l}1 \\
0.08 \text { to } 1.46 \\
0.90 \text { to } 4.95 \\
0.41 \text { to } 1.18 \\
\end{array}$ & $\begin{array}{l}0.15 \\
0.09 \\
0.18 \\
\end{array}$ \\
\hline $\begin{array}{l}\text { CTNNB1 } \\
\text { wild type } \\
\text { mutated }\end{array}$ & $\begin{array}{l}558 \\
137 \\
\end{array}$ & 1.76 & 0.98 to 3.13 & 0.06 \\
\hline $\begin{array}{l}\text { MELF } \\
\text { none } \\
\text { present }\end{array}$ & $\begin{array}{l}594 \\
101 \\
\end{array}$ & 0.63 & 0.28 to 1.41 & 0.26 \\
\hline
\end{tabular}

Result(s)* MELF pattern of invasion was identified in 129 $(16 \%)$ cases, and was associated with grade 1-2 and deep myometrial invasion (table 1). MELF positive tumours were significantly more often found in the no-specific-molecularprofile (NSMP) subclass $(n=95,84.8 \%)$. Of these NSMP MELF positive tumours 91.1\% were CTNNB1-wildtype $(\mathrm{n}=82)$ and $26.5 \% \mathrm{KRAS}$-mutated $(\mathrm{n}=22)$. Uncorrected survival analysis showed a significantly favourable impact of MELF on risk of recurrence $(p=0.031)$. After correction for stage, grade, LVSI, molecular EC class, L1CAM and CTNNB1, MELF pattern of invasion did not significantly impact clinical outcome (HR 0.63 95\%CI 0.28 - 1.41, p=0.26), table 2 .

Conclusion* MELF-pattern of invasion was identified in $16 \%$ of early stage (high)intermediate risk EC, and had no independent prognostic impact. However, our results show that MELF pattern of invasion is more frequently found in NSMP KRAS-mutated EC without CTNNB1 mutations. These distinct molecular features could contribute to further refinement of the NSMP-subgroup of EC pointing to potential novel treatment targets.

\section{A DIAGNOSIS OF INFLAMMATORY MYOFIBROBLASTIC TUMOUR FOLLOWING LAPAROSCOPIC MYOMECTOMY WITH MORCELLATION: A CASE REPORT AND REVIEW OF THE LITERATURE}

${ }^{1} \mathrm{KW}$ Lee*, ${ }^{2} \mathrm{ZY} \mathrm{Ng},{ }^{3} \mathrm{~S}$ Mansor, ${ }^{2} \mathrm{IM}$ Aggarwal. 'KK Women's and Children's Hospital, Obstetrics and Gynaecology, Singapore; 'KK Women's and Children's Hospital, Gynaecological Oncology, Singapore; ${ }^{3} K K$ Women's and Children's Hospital, Pathology and Laboratory Medicine, Singapore

\subsection{6/ijgc-2021-ESGO.170}

Introduction/Background* Inflammatory myofibroblastic tumours (IMT) are rare spindle cell neoplasms of indeterminate malignant potential, commonly found in the lungs, but also originating from various organs ranging from head and neck, gastrointestinal to the genitourinary system. IMTs of the female gynaecological tract are rare and may mimic benign leiomyoma in both clinical presentation and appearance on imaging. We describe a case of uterine IMT, diagnosed after a laparoscopic myomectomy with in-bag morcellation.

Methodology
Result(s)* A 37-year-old woman was on follow-up for uterine mass on pelvic ultrasound, slowly enlarging to $3.3 \mathrm{~cm}$, presumed to be a fibroid. Although she did not have significant pressure symptoms or menorrhagia, she requested for removal and underwent laparoscopic myomectomy with morcellationin-bag.

Intra-operatively, a $6 \mathrm{~cm}$ mass was seen on the uterine posterior wall, macroscopically and morphologically consistent with that of benign leiomyoma. However, immunohistochemistry and molecular sequencing were positive for ALK-1 hence a diagnosis of IMT was made. Diffuse staining for desmin, $\mathrm{H}$ caldesmon and ER was also noted. Following a multi-disciplinary tumour board, consensus was for a CT scan of the thorax, abdomen and pelvis(which showed no extra-uterine spread) and for regular surveillance scans.

A review of the literature shows no universal consensus as to optimal treatment of uterine IMT. Majority of cases have been treated with surgical excision - open, laparoscopic or hysteroscopic. While most cases have a benign course with no recurrence/relapse, local recurrences are a known complication.

Given controversies in recent years over power morcellation potentially leading to dissemination of undiagnosed uterine leiomyosarcomas, morcellation-in-bag has become standard practice for all laparoscopic myomectomies or hysterectomies requiring morcellation. There is little data regarding outcomes of other types of uterine tumours, or IMT specifically, with regards to outcomes following morcellation. The only two documented cases in the literature specifically involving morcellation resulted in local recurrences requiring further treatment.

Conclusion* We present a case of uterine IMT diagnosed following laparoscopic myomectomy and in-bag morcellation. While the patient has no sign of extrauterine spread at present, further follow-up will be required to monitor for any progression or recurrence. Outcomes following morcellation or specific other treatment options will need to be further studied.

\section{IMPLEMENTATION OF COLLABORATIVE TRANSLATIONAL RESEARCH (TRANSPORTEC) FINDINGS IN AN INTERNATIONAL ENDOMETRIAL CANCER CLINICAL TRIALS PROGRAM (RAINBO)}

${ }^{1} \mathrm{~T}$ Bosse, ${ }^{2} \mathrm{M}$ Powell, ${ }^{3} \mathrm{E}$ Crosbie, ${ }^{4} \mathrm{~A}$ Leary, ${ }^{5} \mathrm{~J}$ Kroep, ${ }^{6} \mathrm{~K}$ Han, ${ }^{7} \mathrm{~J}$ Mcalpine, ${ }^{8} \mathrm{~N}$ Horeweg, ${ }^{8} \mathrm{~S}$ De Boer, ${ }^{9} \mathrm{M}$ De Bruyn, ${ }^{8} \mathrm{R}$ Nout, ${ }^{1} \mathrm{~V}$ Smit, ${ }^{9} \mathrm{HW}$ Nijman, ${ }^{10} \mathrm{~N}$ Singh, ${ }^{11} \mathrm{H}$ Mackay, ${ }^{3} \mathrm{R}$ Edmondson, ${ }^{12} \mathrm{~L}$ Mileshkin, ${ }^{13} \mathrm{D}$ Church, ${ }^{14} \mathrm{H}$ Kitchener, ${ }^{8} \mathrm{CL}$ Creutzberg. ${ }^{1}$ Leiden University ,Medical Center (LUMC), Pathology, Leiden, Netherlands; ${ }^{2}$ Barts Health NHS Trust, Clinical Oncology, London, UK; ${ }^{3}$ Manchester Academic Health Science Centre, St Mary's Hospital, Obstetrics and Gynaecology, Manchester, UK; ${ }^{4}$ Gustave Roussy Cancer Center, INSERM U981, Université Paris Saclay, Cancer Medicine and Gynecological Tumor Translational Research Lab, Villejuif, France; ${ }^{5}$ Leiden University Medical Center (LUMC), Medical Oncology, Leiden, Netherlands; ${ }^{6}$ Princess Margaret Cancer Centre, University of Toronto, Radiation Oncology, Toronto, Canada; ${ }^{7}$ University of British Columbia, Obstetrics and Gynecology, Vancouver, Canada; ${ }^{8}$ Leiden University Medical Center (LUMC), Radiation Oncology, Leiden, Netherlands; ' University Medical Center Groningen, Gynaecological Oncology, Groningen, Netherlands; ${ }^{10}$ Barts Health NHS Trust, Cellular Pathology, London, UK; ${ }^{11}$ Odette Cancer Center, Sunnybrook Health Sciences Centre, Medical Oncology, Toronto, Canada; ${ }^{12}$ Peter MacCallum Cancer Centre, Department of Medical Oncology, Melbourne, Australia; ${ }^{13}$ Oxford University Hospitals NHS Foundation Trust, Oxford NIHR Comprehensive Biomedical Research Centre, Oxford, UK; ${ }^{14}$ Institute of Cancer Sciences, University of Manchester, Women's Cancer Centre, Manchester, UK

10.1136/ijgc-2021-ESG0.171 